\title{
IGF1 mRNA isoform expression in the cervix of HPV-positive women with pre-cancerous and cancer lesions
}

\author{
MARIA MAGDALENA KOCZOROWSKA ${ }^{1}$, ANNA KWASNIEWSKA $^{2}$ and ANNA GOZDZICKA-JOZEFIAK ${ }^{1}$ \\ ${ }^{1}$ Department of Molecular Virology, Adam Mickiewicz University, 61-614 Poznan; \\ ${ }^{2}$ Department of Obstetrics and Gynecology, Medical University, 0-081 Lublin, Poland
}

Received September 27, 2010; Accepted November 22, 2010

DOI: $10.3892 /$ etm.2010.174

\begin{abstract}
Human papillomavirus (HPV) plays a crucial role in cervical cancer etiology. However, not all HPV-infected women develop cancer, indicating that additional cellular factors facilitate carcinogenesis. The aim of this study was to analyze the expression profile of insulin-like growth factor 1 (IGF1) isoforms in the context of FOX2, SP1 and IGF1 receptor (IGF1R) expression during HPV-dependent cervical carcinogenesis. One hundred and nine epithelial tissue samples from women with pre-cancerous and cancer lesions of the cervix were analyzed. HPV DNA was identified by PCR, and real-time PCR was used to quantify the expression levels of the analyzed genes. All IGF1 mRNA splicing isoforms were up-regulated in pre-cancerous cells, and a shift in the balance towards mitogenic IGF1Eb was observed in the cancer samples. IGF1 expression was controlled mainly by the $\mathrm{P} 1$ promoter, and an increase in P2 usage was observed in the cancer. Correlations between IGFI mRNA splicing isoforms and the FOX2 splicing factor, as well as P1/P2 activity and SP1 transcription factor expression levels were detected. No correlation was observed between the expression of IGF1 and its receptor IGF1R. Our results suggest that IGF1, in particular its splicing profile, may be an additional prognostic factor in cervical carcinogenesis.
\end{abstract}

\section{Introduction}

Genital human papillomavirus (HPV) infectious types HPV16/18 are very common in numerous populations. However, more than $90 \%$ of genital HPV infections regress without intervention within a short period of time. The remaining $5-10 \%$ of $\mathrm{HPV}$-infected patients develop long-term infections, and such persistent infections are associated with

Correspondence to: Maria Magdalena Koczorowska, Department of Molecular Virology, Institute of Experimental Biology, Adam Mickiewicz University, Umultowska 89, 61-614 Poznan, Poland E-mail: kmarysia@amu.edu.pl

Key words: insulin-like growth factor 1, splicing, cervical cancer, human papillomavirus an increased risk of developing cervical cancer (1). This suggests that, apart from HPV, other factors or co-factors are involved in this process (2). To date, little is known regarding the cellular factors that may facilitate cervical carcinogenesis. In searching for factors responsible for susceptibility to persistent HPV infection, our study focused on insulin-like growth factor 1 (IGF1) protein. IGF1 is one of the cellular factors involved in a variety of cellular processes, such as cell proliferation, differentiation and apoptosis.

IGF1 exerts its effect mostly by binding the specific receptor, IGF1 receptor (IGF1R), which causes autophosphorylation of its $\beta$ subunit and, therefore, initiates a cascade of downstream kinase activation (3). IGF1R mediates IGF1 actions on all cell types, and these actions reveal diversity in terms of tissue specificity and developmental stage (4). The IGF1 protein is expressed mostly in the liver; however, tissue-specific expression is also evident. Thus, IGF1 exhibits both endocrine and auto/paracrine activity, respectively. The circulating fraction of IGF1 is transported bound to IGF1 binding proteins (IGF1BPs) types 1-6. The main transporter is IGF1BP3, which modulates the bioactivity of IGF1 by limiting its access to IGF1R (5).

The IGF1 gene is located on chromosome 12 and extends over $85 \mathrm{~kb}$. The gene comprises six exons separated by long introns. Transcription starts from one of the two possible promoters (P1 and P2) located in exons 1 and 2, respectively. Exons 1 and 2 are differently spliced to exon 3, producing alternative class 1 and class 2 transcripts. The biochemical mechanisms controlling the usage of IGF1 promoters are unresolved. Both $\mathrm{P} 1$ and $\mathrm{P} 2$ regulate transcription over scattered start sites, and it is suggested that heterogeneous transcription initiation compensates for the lack of typical proximal promoter elements, such as TATA- or CCAAT-boxes (6). In both IGF1 gene promoters, multiple specificity protein 1 (SP1) binding elements are present, which indicates that SP1 may be an important IGF1 transcription regulator. SP1 is a sequence-specific ubiquitous transcription factor that binds with high affinity to GC-boxes, and to GT- and CT-boxes with significantly lower affinity (7).

By contrast, exons 5 and 6 demonstrate alternative splicing patterns, which give rise to six IGF1 precursors: classes 1A and $2 \mathrm{~A}$ contain exons 3-4 and 6 of the transcript and form the IGF1Ea isoform with C-terminal Ea extension peptide. Classes $1 \mathrm{~B}$ and $2 \mathrm{~B}$ contain exons 3-5 (IGF1Eb isoform), and class $1 \mathrm{C}$ 
and $2 \mathrm{C}$ isoform (IGF1Ec) arises from an internal splice site within exon 5, which links 49 nucleotides of exon 5 to exon 6.

All of these propeptides undergo subsequent proteolytic processes and eventually result in one mature $70-\mathrm{kDa}$ IGF1 protein encoded by exons 3 and 4, which is either released into the bloodstream or into the extracellular matrix (8). The physiological role of propeptides and alternative E peptides generated from isoforms IGF1Ea, IGF1Eb and IGF1Ec remains unclear. It has been proposed that different IGF1 propeptides have distinct biological effects and may act through various signaling pathways (9). Little is known about the regulation of IGF1 pre-mRNA splicing. One of the putative factors implicated in this process is FOX2 (RNA binding motif protein 9; RMB9), a splicing regulator that binds exclusively to the UGCAUG and AGCAUG sites downstream or upstream of the alternatively spliced exons. Notably, FOX2 acts both as an enhancer and silencer of splicing, depending on the location of the binding site (10-12).

It has previously been observed that up-regulation of the circulating IGF1 level is correlated with several types of cancer, including prostate, breast, colorectal and lung cancer, which suggests a role for IGF1 as a risk factor for cancer (4). Numerous studies have focused mostly on the measurement of circular IGF1, while its role as a tissue growth factor has been underestimated. Little is known about IGF1 tissue expression in cervical cancer cells, and the available data are inconsistent $(13,14)$.

The turning point in studies on IGF1 action was the detection of the IGF1Eb isoform in the nucleus of human cells by Tan et al (15). Also, our previous immunohistochemical studies indicated the presence of IGF1 in the nuclei of a reproductive layer of paraepidermal epithelium in intraepithelial neoplasia (low-grade squamous intraepithelial neoplasia; L-SIL, and high-grade squamous intraepithelial neoplasia; H-SIL) and in cervical cancer cells. The nuclear localization of IGF1 suggests that it may also have intranuclear activity (13).

The aim of our study was to evaluate the expression of total IGF1 and IGF1 isoforms (IGF1Ea, IGF1Eb and IGF1Ec) in HPV-positive cervix samples in women with pre-cancerous (L-SIL and H-SIL) and cancer lesions in relation to control HPV-negative cervix. In addition, we analyzed the usage of $I G F 1$ gene promoters $\mathrm{P} 1$ and $\mathrm{P} 2$ in study cells as well as the transcription factor SP1, splicing factor FOX2 and IGF1R expression levels.

\section{Materials and methods}

Research material. The study was performed in a group of 109 women aged 23 to 61 years (median 49). There were no significant differences in the mean age of women who underwent surgery for squamous cell cervical carcinoma compared to the control women. However, the women with H-SIL a statistically lower mean age compared to the women with squamous cell cervical carcinoma and the controls $(\mathrm{p}<0.05)$.

Among the patients, 87 were treated for L-SIL, H-SIL and squamous cell cervical carcinoma between 2007-2009 at the Department of Gynecology and Obstetrics, Medical University of Lublin, Poland. The study was approved by the Ethics Committee of the Medical University of Lublin. Cervical cells were collected from the study subjects via cervical scrape.
For cancer and neoplasmatic cell localization, all specimens initially underwent H\&E staining followed by pathological review. Cervical sections comprised of at least $70 \%$ cancer cells were used as cancer samples. The tissue samples were frozen immediately in liquid nitrogen and stored at $-80^{\circ} \mathrm{C}$ until further use.

The study group consisted of postoperative tissues from patients diagnosed with L-SIL $(n=28)$, H-SIL $(n=30)$ and squamous cell cervical carcinoma $(n=29)$. The control group $(n=22)$ consisted of normal cervical tissue specimens obtained from patients undergoing hysterectomy due to uterine leiomyomas.

Histopathological criteria formulated by the World Health Organization (WHO) were used to establish the diagnosis of squamous cell cervical carcinoma (16). With respect to the dedifferentiation of neoplastic cells, all patients were classified as G2 with moderately differentiated squamous cell carcinomas (WHO grading G1-G3). According to FIGO clinical staging, among the squamous cell cervical carcinoma tissues, 15 patients were at stage I and 14 at stage IIA (17).

HPVidentification. Genomic DNA was isolated from the study tissues using the QIAamp DNA Midi kit (Qiagen) according to the manufacturer's protocol. The purity and concentration of genomic DNA was analyzed spectrophotometrically. HPV infection was identified by PCR amplification of the HPV gene sequence using primers MY09 and MY11 complementary to the genome sequence of at least 33 types of HPV viruses as described previously (18). The reaction mixture contained $15 \mathrm{ng} / \mu 1$ DNA and the following reagents: 0.5 units Taq DNA polymerase (Fermentas), PCR buffer and magnesium chloride (Fermentas) at the final concentration of $1.5 \mathrm{mM}$, primers at the final concentrations of $0.25 \mathrm{mM}$ each and dNTPs (Promega) at the final concentration of $0.2 \mathrm{mM}$. PCR products were run in $1.2 \%$ agarose gel electrophoresis with ethidium bromide and visualized under UV light. The product length was assessed according to MassRuler marker (Fermentas). PCR products were randomly eluted from agarose gel using the QIAquick Gel Extraction kit (Qiagen) and sequenced. The sequencing results were computationally analyzed using the BLAST database (http://blast.ncbi.nlm.nih.gov).

RNA extraction and cDNA synthesis. Total RNA was extracted using the RNeasy-Fibrous Tissue mini-kit (Qiagen) according to the manufacturer's protocol. RNA purification included double DNase treatment. RNA quantification was performed spectrophotometrically, and the quality was assessed by agarose-formaldehyde gel electrophoresis.

For each sample, after gDNA removal, $1 \mu \mathrm{g}$ RNA was converted into first-strand cDNA in a reverse transcription reaction using the QuantiTect Reverse Transcription kit (Qiagen) following the manufacturer's instructions.

Primers. The primers used for real-time PCR are presented in Table I.

Primers specific to the human $I G F 1$ gene were designed according to sequence number NT_019546.15. Primers to quantify total IGF1 were complementary to constitutive exons 3 and 4 (13). In order to distinguish IGF1 mRNA isoforms, primers were complementary to different exons. To 
Table I. Primers used in real-time PCR and PCR product sizes.

\begin{tabular}{|c|c|c|c|}
\hline Gene/isoform & Primer sequence & Fragment length (bp) & Annealing temperature $\left({ }^{\circ} \mathrm{C}\right)$ \\
\hline IGF1 & $\begin{array}{l}\text { GCTCTTCAGTTCGTGTGTGG } \\
\text { TGACTTGGCAGGCTTGAGG }\end{array}$ & 171 & 60 \\
\hline IGF1Ea & $\begin{array}{l}\text { TCGTGGATGAGTGCTGCTTCCG } \\
\text { TCAAATGTACTTCCTTCTGGGTCTTG }\end{array}$ & 144 & 60 \\
\hline IGF1Eb & $\begin{array}{l}\text { ATCTACCAACAAGAACACG } \\
\text { TACТTCCAАТСТСССТСC }\end{array}$ & 140 & 56 \\
\hline IGF1Ec & $\begin{array}{l}\text { ACCAACAAGAACACGAAGTC } \\
\text { CATGTCACTCTTCACTCСTC }\end{array}$ & 126 & 58 \\
\hline Class 1 IGF1 (P1) & $\begin{array}{l}\text { CAGCAGTCTTCCAACCCA } \\
\text { CACAGCGCCAGGTAGAAGAGATGC }\end{array}$ & 102 & 61 \\
\hline Class 2 IGF1 (P2) & $\begin{array}{l}\text { CACCTACAGTGAAGATGCACACC } \\
\text { CGTCTCCGGTCCAGCCGTGGC }\end{array}$ & 101 & 67 \\
\hline FOX2 & $\begin{array}{l}\text { CGAGAATAGTGCTGATG } \\
\text { GGTCTTACACGTGCTGTAG }\end{array}$ & 103 & 55 \\
\hline SP1 & $\begin{array}{l}\text { CCCAACCCCAAGCCGGTC } \\
\text { CCCCCGAGCCCCTTCC }\end{array}$ & 85 & 65 \\
\hline IGF1R & $\begin{array}{l}\text { GGGAATGGAGTGCTGTATG } \\
\text { CACAGAAGCTTCGTTGAGAA }\end{array}$ & 258 & 60 \\
\hline RPLP0 & $\begin{array}{l}\text { CCTCATATCCGGGGGAATGTG } \\
\text { GCAGCAGCTGGCACCTTATTG }\end{array}$ & 95 & 56 \\
\hline GAPDH & $\begin{array}{l}\text { AAGGTCGGAGTCAACGGATTT } \\
\text { ACCAGAGTTAAAAGCAGCCCTG }\end{array}$ & 60 & 58 \\
\hline
\end{tabular}

amplify isoform IGF1Ea, the primers were complementry to sequences in exons 4 and 6 ; for isoform IGF1Eb, exons $5 a$ and $5 \mathrm{~b}$; for IGF1Ec, exons $5 \mathrm{a}$ and 6 . To specifically indicate transcripts class I derived from the $\mathrm{P} 1$ promoter, primers were complementary to exons 1 and 3 , and for class II, exons $2 / 3$ and 3 .

Other real-time PCR primers were used to quantify SP1. Primers for IGF1R and the reference genes GAPDH and RPLP0 were as previously described $(14,19)$.

Primer specificity was assessed by a PCR reaction. The PCR reaction was carried out in a final volume of $10 \mu \mathrm{l}$, and the mixture contained $15 \mathrm{ng} / \mu \mathrm{l} \mathrm{cDNA}$ and the following reagents: 0.5 units Taq DNA polymerase, PCR buffer and magnesium chloride at the final concentration of $1.5 \mathrm{mM}$, primers at the final concentrations of $0.25 \mathrm{mM}$ each, and dNTPs at the final concentration of $0.2 \mathrm{mM}$. The reaction was run under the following conditions: initial denaturation at $90^{\circ} \mathrm{C}$ for $10 \mathrm{~min}$, followed by 45 cycles of denaturation at $95^{\circ} \mathrm{C}$ for $10 \mathrm{sec}$, annealing (temperature dependant on primer sequences; Table I) and elongation at $72^{\circ} \mathrm{C}$ for $20 \mathrm{sec}$. Each primer pair generated a single product observed as a single band of appropriate size (Table I) in 2\% agarose gel electrophoresis. PCR products were eluted from agarose gel using the QIAquick Gel Extraction kit, and were sequenced to confirm the expected product presence. The sequencing results were computationally analyzed using the BLAST database (http:// blast.ncbi.nlm.nih.gov).
Real-time PCR. Quantitative real-time PCR analysis was performed in an automated fluorometer (Rotor-Gene 6000; Corbett Research) using the SYBR Green PCR master mix (Applied Biosystems, UK). GAPDH and RPLP0 were used as reference genes, and the selection was based on data from a previously described validation study (19). The PCR reaction was carried out at a final volume of $10 \mu \mathrm{l}$ containing $2 \mu \mathrm{l}$ of cDNA, primers at a concentration of $1 \mu \mathrm{M}$ each and SYBR Green PCR master mix. The samples were run in triplicate and placed in a 72-well plate. The reaction was performed under the following conditions: initial denaturation at $90^{\circ} \mathrm{C}$ for $10 \mathrm{~min}$, followed by 45 cycles of denaturation at $95^{\circ} \mathrm{C}$ for $10 \mathrm{sec}$, annealing (temperature dependant on primer sequences; Table I) and elongation at $72^{\circ} \mathrm{C}$ for $20 \mathrm{sec}$. PCR products were quantified according to the standard curves produced by amplification of the serial dilutions, and the expected product was verified according to the melting point.

Statistical analysis. The measured parameters were statistically evaluated as quotient scales by means of the median, lower and upper quartile with range of trait variability. Because of the skewed distribution of the analyzed parameters evaluated by the Shapiro-Wilk W test or non-homogeneous variance calculated by the Fischer F test, non-parametric tests were used to analyze differences between subgroups. The Kruskal-Wallis test and multiple post hoc analysis were used for the comparison of more than two groups. Spearman's rank correlation coefficient 

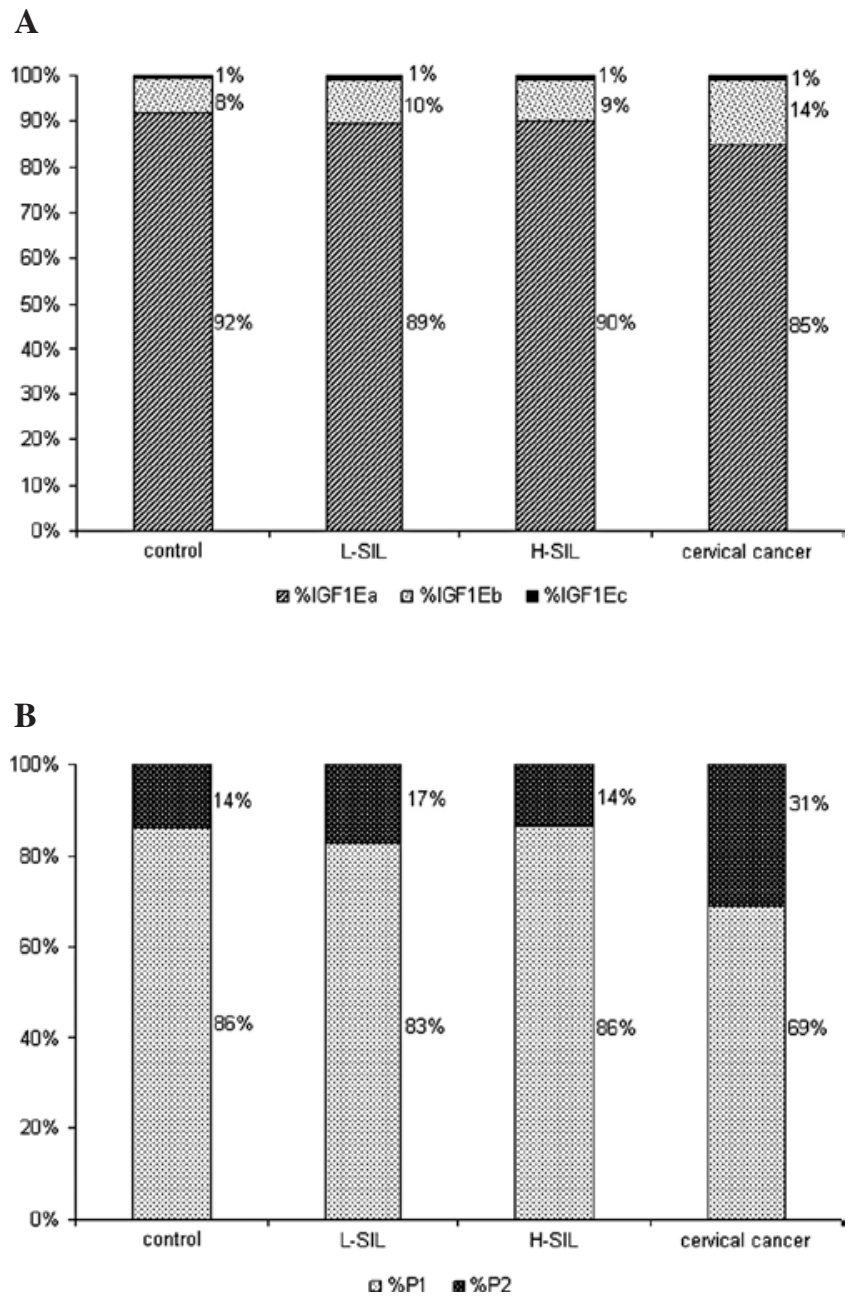

Figure 1. (A) Percentage of IGF1 mRNA isoform expression (IGF1Ea, IGF1Eb and IGF1Ec), and (B) percentage of $\mathrm{P} 1$ and $\mathrm{P} 2$ promoter activity in relation to total IGF1 (100\%) expression at various stages of cervical carcinogenesis.

(R) was used for the assessment of the relationship between subgroups. Levels of significance with $5 \%$ error $(\mathrm{p}<0.05)$ were chosen to calculate the statistical significance of differences or correlations. The obtained results are presented in the tables and figures. All calculations were carried out using the Statistica 7.1 software package (StatSoft, Poland).

\section{Results}

The research material underwent HPV identification. For the study, 109 samples were selected and divided into HPV-negative controls and HPV-positive L-SIL, H-SIL and cancer cells.

Using the real-time PCR technique, all possible IGF1 mRNA isoforms were identified in the pre-cancer, cancer and control epithelial cells of the cervix samples.

The predominant splicing isoform in all study cells was IGF1Ea (85-92\%). The expression of the IGF1Eb isoform, which was differential and dependent on the stage of carcinogenesis, ranged between $8 \%$ in the control tissue and $14 \%$ in the cervical cancer. The expression of the IGF1Ec isoform appeared to be at the lowest level and was consistently
Table II. Statistical analysis of the expression of IGF1 mRNA isoforms, promoter activity and total IGF1 expression correlated with mRNA expression levels of FOX2, SP1 and IGF1R, respectively, at various stages of carcinogenesis.

\begin{tabular}{lcccc}
\hline & Control & L-SIL & H-SIL & $\begin{array}{c}\text { Cervical } \\
\text { cancer }\end{array}$ \\
\hline IGF1Ea and FOX2 & 0.36 & $0.69^{\mathrm{b}}$ & $0.62^{\mathrm{b}}$ & $0.59^{\mathrm{a}}$ \\
IGF1Eb and FOX2 & 0.21 & $0.64^{\mathrm{b}}$ & $0.68^{\mathrm{b}}$ & $0.63^{\mathrm{a}}$ \\
IGF1Ec and FOX2 & 0.25 & $0.61^{\mathrm{b}}$ & $0.64^{\mathrm{b}}$ & 0.52 \\
P1 and SP1 & $0.92^{\mathrm{b}}$ & $0.57^{\mathrm{b}}$ & $0.55^{\mathrm{b}}$ & 0.15 \\
P2 and SP1 & $0.77^{\mathrm{b}}$ & $0.44^{\mathrm{a}}$ & $0.34^{\mathrm{a}}$ & 0.25 \\
Total IGF1 and IGF1R & 0.52 & 0.40 & -0.21 & 0.45 \\
\hline
\end{tabular}

Spearman's rank correlation coefficients for each analyzed relationship

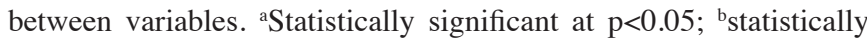
significant at $\mathrm{p}<0.01$.

at $\sim 1 \%$ in all the studied tissues (Fig. 1A). Detailed analysis of the mRNA relative expression levels of each splicing isoform (normalized according to reporter genes) showed up-regulation of all isoforms in L-SIL and H-SIL, compared to the control and the cervical cancer tissue (Fig. 2A-C). Differences between the relative expression of each isoform A-C in H-SIL and cervical cancer were statistically significant $(\mathrm{p}<0.05)$. Additionally, for IGF1Eb, this difference was also statistically significant when compared to L-SIL and cervical cancer.

Promoter usage in the IGFI gene was determined by identification of either exon 1 or exon 2 in the IGF1 transcripts. IGF1 transcription in the studied cells was mostly controlled by the P1 promoter localized in exon 1 (69-86\% of class I transcripts). However, exon 2 was detected in 14-31\% of the transcripts, which indicates considerable P2 promoter activity (class 2 transcripts). The greatest contribution of the P2 promoter in total IGF1 expression was observed in the cervical cancer samples (31\%) (Fig. 1B). Detailed analysis of the relative expression levels showed no significant differences in promoter usage between the cancer, L-SIL, H-SIL and control tissues (Fig. 2D and E).

The mechanism of IGFl pre-mRNA alternative splicing and promoter usage regulation remains unknown. However, the analysis of alternative splicing factor FOX2 expression levels (unpublished data) showed a statistically significant correlation between the FOX 2 mRNA expression level and an increase in the IGF1Eb isoform (Table II).

SP1 transcription factor, the activator for the P1 and P2 promoter, appeared to be up-regulated in dysplasia (unpublished data), which was correlated with the increased IGF1 level in these tissue samples (Table II). No correlation between SP1 and promoter usage was detected in the cancer tissue.

The expression level of IGF1-specific receptor IGF1R mRNA was also quantified, and was observed to be doubled in the cancer tissue compared to the controls, while slight up-regulation of IGF1R mRNA was observed in neoplasia, L-SIL and H-SIL tissues (unpublished data). No statistically significant correlation was found between tissue IGF1 and IGF1R expression levels (Table II). 
A

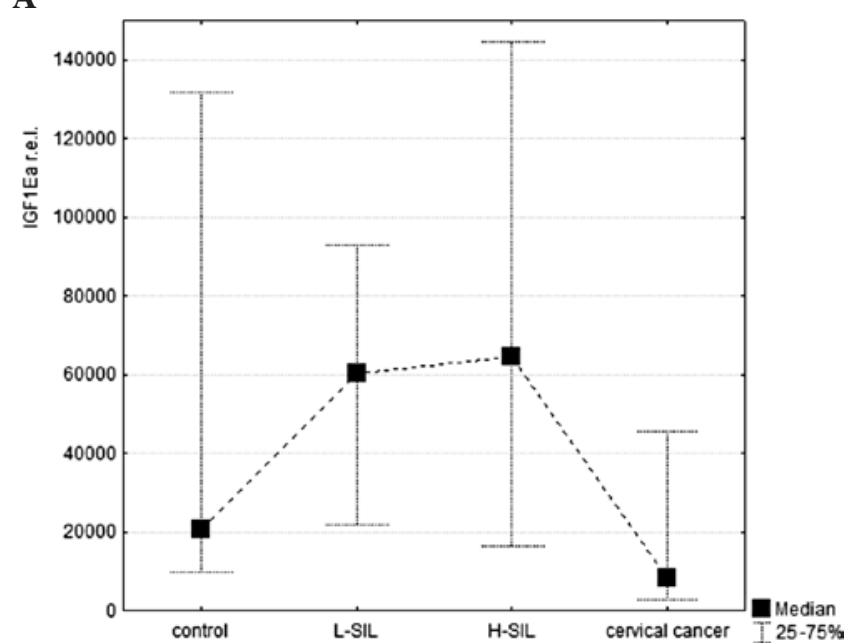

C

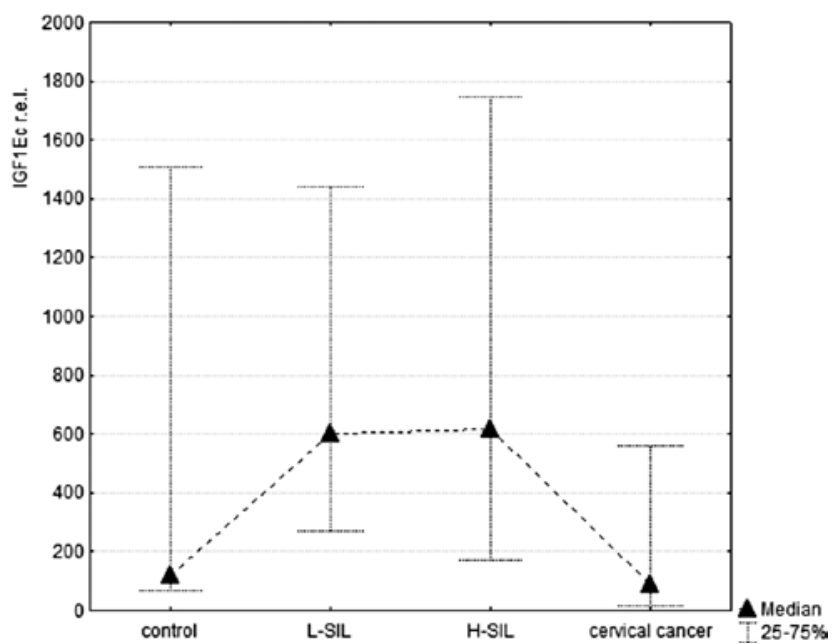

$\mathbf{E}$

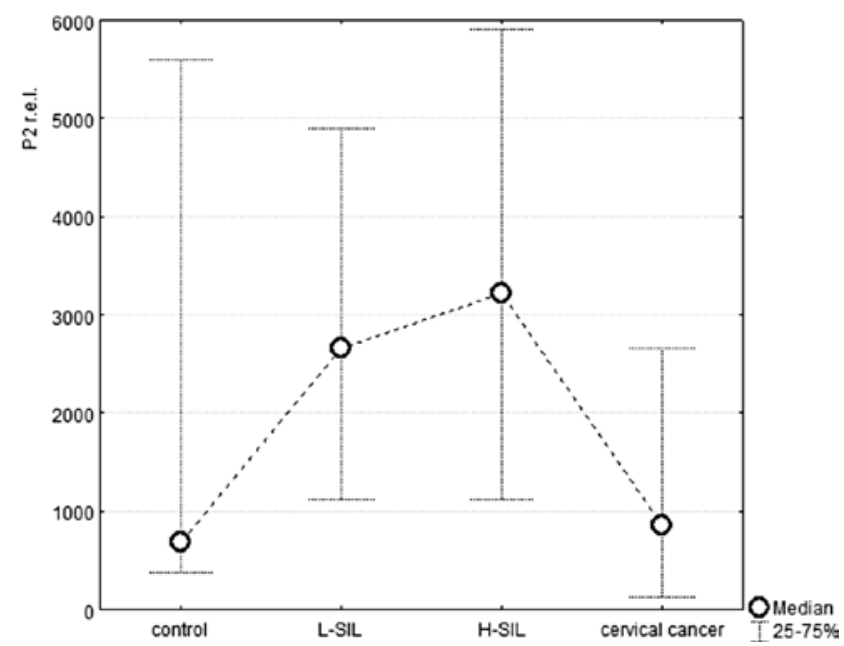

\section{Discussion}

IGF1 is a circulating peptide hormone and a locally acting growth factor with endocrine, paracrine and autocrine functions (3). Recently, a number of studies have focused on the identification of different IGF1 isoforms and the evaluation of their functional significance $(9,20-26)$.
B

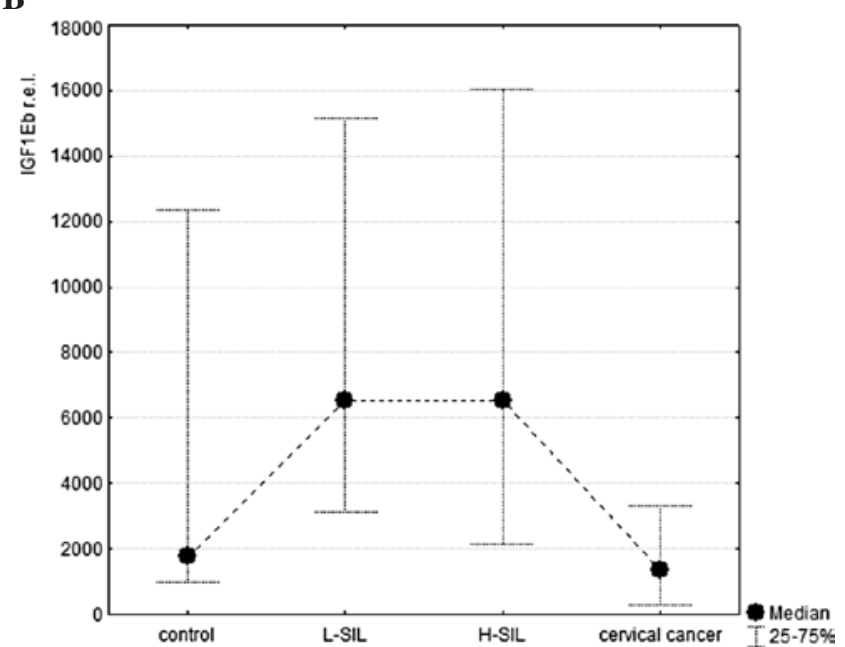

D

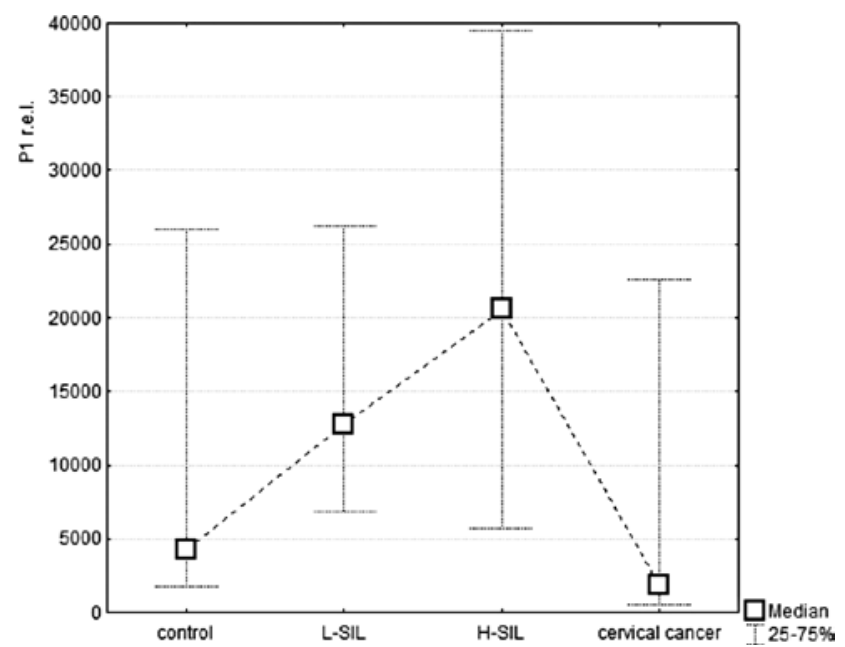

Figure 2. Quantification of total IGF1 mRNA isoforms IGF1Ea, IGF1Eb and IGF1Ec mRNA expression (A-C, respectively) and $\mathrm{P} 1$ and $\mathrm{P} 2$ promoter activity (D and E, respectively) in various stages of cervical carcinogenesis. Presented data are the medians of relative expression level normalized according to GAPDH/RPLPO reporter genes. The differences between relative expression in H-SIL and cervical cancer of each splicing isoform were statistically significant at $\mathrm{p}<0.05$. Additionally, for IGF1Eb this difference was statistically significant also between L-SIL and cervical cancer.

The physiological differences between the functions of the local and circulating fraction of IGF1 have not been completely established. However, it has been proposed that different IGF1 isoforms (IGF1Ea, IGF1Eb and IGF1Ec) have various functions in muscle repair and growth (20). After injury to skeletal muscle, the IGF1Eb mRNA splice variant is initially up-regulated, followed by up-regulation of the IGF1Ea splice 
variant at later time points. Up-regulation of IGF1Eb mRNA correlates with myoblast proliferation, whereas up-regulation of IGF1Ea mRNA is linked to differentiation into mature myofibers $(21,22)$. Other studies have indicated that the locally acting IGF1 isoform also has neuroprotective effects and protects cardiomyocytes from hypertrophic and oxidative stress $(9,23,24)$. Ohtsuki et al, using the PCR method, demonstrated that IGF1Ea mRNA was more abundant than IGF1Eb mRNA in a number of organs (uterus, ovary, liver and kidney) in the mouse, and was both organ specifically and temporally regulated (25). Additionally, it has been suggested that E-peptides modulate the cell entry of mature IGF1 (26).

In our study, we detected all three IGF1 isoforms in the HPV-positive L-SIL, H-SIL and cancer tissues as well as in the HPV-negative control cervical epithelium. However, we observed increased mRNA expression of all IGF1 isoforms in L-SIL and H-SIL compared to normal cervix and the cervix of women with cervical cancer (Fig. 2A-C). Notably, the percentage contribution of isoform IGF1Eb to total IGF1 expression was higher in cervical cancer compared to that in other stages of carcinogenesis (Fig. 1A). We suggest that this shift in the balance between IGF1 isoforms towards mitogenic IGF1Eb in cervical cancer cells may be significant in cancer progression. It has previously been suggested that E-peptides may have functions distinct from mature IGF1. Siegfried et al demonstrated that E-peptide derived from the IGF1Eb isoform exhibits mitogenic activity (25). Later, it was shown that E-peptides increase IGF1 uptake into cells and enhance mature IGF1 activity (26). Therefore, we propose that a shift in the ratio of IGF1Ea to IGF1Eb isoforms towards IGF1Eb may also serve as a biomarker for the prognosis of cervical cancer development.

Furthermore, up-regulation of the IGF1Eb isoform in cervical cancer was found to correspond to simultaneous expression of HPV viral E6 and E7 proteins during the late stages of neoplasia (1). HPV viral early proteins are involved in a variety of intracellular processes, including splicing. It has previously been demonstrated by Bell et al that HPV E4 protein interacts with SR-specific kinase SRPK1, which consequently impairs spliceosome assembly (27). In addition, Bodaghi et al showed that HPV16 proteins E2 and E6 are RNA-binding proteins and may affect splicing both by binding directly to pre-mRNA and by interacting with splicing factors (28). It was previously described that HPV proteins also regulate gene expression at the transcriptional level and affect splicing by the up-regulation of splicing factors. In fact, the HPV E2 protein acts as a transcription factor, not only in terms of viral gene regulation, but also by altering the expression of multiple cellular genes, including splicing factors SR (arginine/serine-rich splicing factor protein family), splicing factor 2/alternative splicing factor (SF/ASF) and heterogeneous nuclear ribonucleoprotein A1 (hnRNPA1) $(29,30)$.

A gradual increase in the expression level of the FOX2 splicing factor in cervical epithelium upon cervical carcinogenesis has been observed. These results are consistent with data obtained by Venables et al for breast cancer, but differ from those found for ovarian cancer (31). It has been suggested that downstream sites demonstrate the character of the splicing enhancer, while upstream sites function as silencers (12).
In the IGF 1 gene, the FOX 2 putative binding sites are the upstream exon 5 and downstream exon 6 . Our results indicate that the up-regulation of FOX2 may prevent the exclusion of exon 5 and at the same time enhance the exclusion of exon 6 , which results in the up-regulation of the IGF1Eb isoform and a reduction of IGF1Ea in dysplasia and cervical cancer tissue. This putative mechanism resulted in correlations between IGF1 mRNA splicing isoforms and FOX2 expression levels (Table II).

In this study, we found that the up-regulation of total IGF1 expression, which is mostly controlled by P1, was increased in both stages of neoplasia (L-SIL and H-SIL) (Fig. 2D and E). The mechanism of preferential transcription initiation from the $\mathrm{P} 1$ promoter as well as increased $\mathrm{P} 2$ usage in cancer (Fig. 1B) remains unresolved. However, HPV proteins, which are overexpressed in neoplasia (e.g., E2) (1), may be involved in the regulation of $I G F 1$ promoter activity. Furthermore, we demonstrated the up-regulation of SP1 transcriptional factor in HPV-positive tissues (unpublished data). Of note, SP1 binding sites have been found in both the P1 and $\mathrm{P} 2$ IGF 1 promoters. Thus, we suggest that the correlation of SP1 expression with $\mathrm{P} 1$ and $\mathrm{P} 2 I G F 1$ promoter activity in neoplasia is related to the up-regulation of $I G F 1$ expression caused by SP1 action. It has not only been suggested that SP1 activates IGF1, but that the SP1 binding site is also a target of IGF1 action in other genes activated in cancer (32), which may be an additional explanation for the considerably strong correlation between the expression levels of these factors (Table II). In addition, the SP1-binding site is also situated in the HPV E6/E7 promoter region, and is probably the only one recognized by cellular transcription factors essential for the function of early transcription initiation $(33,34)$. Thus, we suggest that the up-regulation of SP1 during the early stage of dysplasia may provoke expression of the HPV oncogenic proteins E6 and E7, and may therefore serve as a prognostic factor for cancer development. Additionally, recent studies on SP1 expression upon HPV infection showed concurrent expression of SP1 with L1 proteins in differentiating keratinocytes in mice (35).

Measurement of the expression level of the IGF1-specific receptor IGF1R revealed a significant up-regulation in cervical cancer tissue (unpublished data). This result is consistent with previously described data obtained in mice, where the overexpression of IGF1R facilitated tumor development $(36,37)$. Moreover, increased expression of IGF1R has been linked to several cancer types in humans $(38,39)$. It has been proposed that the up-regulation of IGF1R in cancer cells may be due to loss of transcriptional control by major tumor-suppressor genes (40). Additionally, immunohistochemistry with an antiIGF1R antibody revealed that the expression levels of IGF1R in H-SIL and invasive squamous cell carcinoma were higher than the level in normal cervical epithelial cells. Kuramoto et al showed that the distribution of IGF1R overexpression in L-SIL and H-SIL was co-localized with that of HPV E6 oncoprotein expression (41). We did not find any significant correlation between IGF1R and the local expression of total IGF1 (Table II). However, this result can be explained by the fact that our study focus was on locally expressed IGF1, while IGF1R is activated not only by the local, but also by the circular IGF1 fraction (5). 
Taken together, our results demonstrate the differential expression of IGFI mRNA splicing isoforms in HPV-positive pre-cancerous and cervical cancer cells compared to HPV-negative control tissue. Both IGFI promoters appeared to be active in normal and tumorous cervical cells; however, the balance between them was unequal. Moreover, we demonstrated a strong correlation in the expression of IGF1 isoforms with cellular factors FOX2 and SP1.

Thus, we suggest that the role of IGF1 in the development and progression of cervical cancer appears to be more complex than previously described. In particular, due to the up-regulation of the IGF1Eb isoform with mitogenic properties, its significance in cancerogenesis may be more pronounced. Although the impact of HPV infection on the course of IGF1 pre-mRNA splicing as well as on IGF1 promoter activation has not yet been resolved, numerous research results have demonstrated that HPV proteins may impair this process. Furthermore, HPV proteins affect splicing both directly, as spliceosome components, and indirectly, via the activation of splicing factors.

Further investigation towards a better understanding of the mechanisms of IGF1 expression in HPV-infected cells will be helpful to develop highly sensitive and multifactorial tools for the prevention, diagnosis and treatment of cervical cancer.

\section{Acknowledgements}

This study was supported by the ministry of Higher Education in Poland, grant no. N N401219824. The authors acknowledge Dr Agata Smolen and Professor Maria Kaczmarek for their assistance with the statistical analysis.

\section{References}

1. Doorbar J: Molecular biology of human papillomavirus infection and cervical cancer. Clin Sci 110: 525-541, 2006.

2. Madkan VK, Cook-Norris RH, Steadman MC, Arora A, Mendoza N and Tyring SK: The oncogenic potential of human papillomaviruses: a review on the role of host genetics and environmental cofactors. Br J Dermatol 157: 228-241, 2007.

3. Samani AA, Yakar S, LeRoith D and Brodt P: The role of the IGF system in cancer growth and metastasis: overview and recent insights. Endocr Rev 28: 20-47, 2007.

4. Cohen P: Overview of the IGF-I system. Horm Res 65 (Suppl 1): 3-8, 2006.

5. Pollak M: Insulin and insulin-like growth factor signalling in neoplasia. Nat Rev Cancer 8: 915-928, 2008.

6. Mittanck DW, Kim SW and Rotwein P: Essential promoter elements are located within the 5' untranslated region of human insulin-like growth factor-I exon I. Mol Cell Endocrinol 126 153-163, 1997.

7. Wierstra I: Sp1: emerging roles - beyond constitutive activation of TATA-less housekeeping genes. Biochem Biophys Res Commun 372: 1-13, 2008.

8. LeRoith D and Roberts CT Jr: The insulin-like growth factor system and cancer. Cancer Lett 195: 127-137, 2003.

9. Musarò A, Dobrowolny G and Rosenthal N: The neuroprotective effects of a locally acting IGF-1 isoform. Exp Gerontol 42 76-80, 2007.

10. Gee SL, Aoyagi K, Lersch R, Hou V, Wu M and Conboy JG: Alternative splicing of protein 4.1R exon 16: ordered excision of flanking introns ensures proper splice site choice. Blood 95: 692-699, 2000.

11. Baraniak AP, Chen JR and Garcia-Blanco A: Fox-2 mediates epithelial cell-specific fibroblast growth factor receptor 2 exon choice. Mol Cell Biol 26: 1209-1222, 2006.
12. Zhang C, Zhang Z, Castle J, Sun S, Jahnson J, Krainer AR and Zhang MQ: Defining the regulatory network of the tissue-specific splicing factors FOX-1 and FOX-2. Genes Dev 22: 2550-2563, 2008.

13. Jozefiak A, Pacholska-Bogalska J, Myga-Nowak M, Kedzia W, Kwasniewska A, Luczak M, Kedzia H and Gozdzicka-Jozefiak A: Serum and tissue levels of insulin-like growth factor-I in women with dysplasia and HPV-positive cervical cancer. Mol Med Rep 1: 231-237, 2008

14. Serrano ML, Sánchez-Gómez M and Bravo MM: Insulin-like growth factor system gene expression in cervical scrapes from women with squamous intraepithelial lesions and cervical cancer. Growth Horm IGF Res 17: 492-499, 2007.

15. Tan DS, Cook A and Chew SL: Nucleolar localization of an isoform of the IGF-I precursor. BMC Cell Biol 3: 17, 2002.

16. Tavassoli FA and Deville P: World Health Organization Classification of Tumors. Pathology, Genetics. Tumours of the Breast and Female Genital Organs. IRAC Press, Lyon, 2003.

17. Kosary CL: FIGO stage, histology, histologic grade, age and race as prognostic factors in determining survival for cancers of the female gynecological system: an analysis of 1973-87 SEER cases of cancers of the endometrium, cervix, ovary, vulva, and vagina. Semin Surg Oncol 10: 31-46, 1994.

18. Manos MM, Ting Y, Wright DK, Lewis AI, Broker TR and Wolinsky SM: The use of polymerase chain reaction amplification for the detection of genital human papillomaviruses. Cancer Cells 7: 209-214, 1989.

19. Daud II and Scott ME: Validation of reference genes in cervical cell samples from human papillomavirus-infected and -uninfected women for quantitative reverse transcription-PCR assays. Clin Vaccine Immunol 15: 1369-1373, 2008.

20. Philippou A, Papageorgiou E, Bogdanis G, Halapas A, Sourla A, Maridaki M, Pissimissis N and Koutsilieris M: Expression of IGF-1 isoforms after exercise-induced muscle damage in humans: characterization of the MGF E peptide actions in vitro. In Vivo 23: 567-575, 2009.

21. Matheny RW, Nindl BC and Adamo MI: Mechano-growth factor: a putative product of IGF 1 gene expression involved in tissue repair and regeneration. Endocrinology 151: 3865-3875, 2010.

22. Barton ER: The ABC of IGF 1 isoforms: impact on muscle hypertrophy and implication for repair. Appl Physiol Nutr Metab 31: 791-797, 2006.

23. Górecki DC, Beręsewicz M and Zabłocka B: Neuroprotective effects of short peptides derived from the insulin-like growth factor 1. Neurochem Int 51: 451-458, 2007.

24. Vinciquerra M, Santini MP, Claycomb WC, Ladurner AG and Rosenthal N: Local-IGF-1 isoform protects cardiomyocytes from hypertrophic and oxidative stresses via Sirtl activity. Aging (Albany NY): 43-62, 2010.

25. Ohtsuki T, Otsuki M, Murakami Y, Maekowa T, Yamamoto T, Kasaka K, Takenchi S and Takahashi S: Organ-specific and age-dependent expression of insulin-like growth factor-I (IGF-I) mRNA variants: IGF-IA and IB mRNAs in the mouse. Zoolog Sci 22: 1011-1021, 2005.

26. Pfeffer LA, Brisson BK, Lei H and Barton ER: The insulin-like growth factor (IGF)-I E-peptides modulate cell entry of the mature IGF-I protein. Mol Biol Cell 20: 3810-3817, 2009.

27. Bell I, Martin A and Roberts S: The E1^E4 protein of human papillomavirus interacts with the serine-arginine-specific protein kinase SRPK1. J Virol 81: 5437-5448, 2007.

28. Bodaghi S, Jia R and Zheng ZM: Human papillomavirus type 16 E2 and E6 are RNA-binding proteins and inhibit in vitro splicing of pre-mRNAs with suboptimal splice sites. Virology 386: 32-43, 2009.

29. Cheunim T, Zhang J, Milligan SG, McPhillips MG and Graham SV: The alternative splicing factor hnRNP A1 is up-regulated during virus-infected epithelial cell differentiation and binds the human papillomavirus type 16 late regulatory element. Virus Res 131: 189-198, 2008.

30. Mole S, McFarlane M, Chuen-Im T, Milligan SG, Millan D and Graham SV: RNA splicing factors regulated by HPV16 during cervical tumour progression. J Pathol 219: 383-391, 2009.

31. Venables JP, Klinck R, Koh C, et al: Cancer-associated regulation of alternative splicing. Nat Struct Mol Biol 16: 670-676, 2009.

32. Li T, Chen YH, Liu TJ, Jia J, Hampson S, Shan YX, Kibler D and Wang PH: Using DNA microarray to identify Sp1 as a transcriptional regulatory element of insulin-like growth factor 1 in cardiac muscle cells. Circ Res 93: 1202-1209, 2003. 
33. Gloss B and Bernard HU: The E6/E7 promoter of human papillomavirus type 16 is activated in the absence of $\mathrm{E} 2$ proteins by a sequence-aberrant Sp1 distal element. J Virol 64: 5577-5584, 1990 .

34. McPhillips MG, Veerapraditsin T, Cumming SA, Karali D Milligan SG, Boner W, Morgan IM and Graham SV: SF2/ASF binds the human papillomavirus type 16 late RNA control element and is regulated during differentiation of virus-infected epithelial cells. J Virol 78: 10598-10605, 2004.

35. Li B, Wang X, Zhou F, Saunders NA, Frazer IH and Zhao KN: Up-regulated expression of Sp1 protein coincident with a viral protein in human and mouse differentiating keratinocytes may act as a cell differentiation marker. Differentiation 76: 1068-1080, 2008.

36. Carboni JM, Lee AV, Hadsell DL, et al: Tumor development by transgenic expression of a constitutively active insulin-like growth factor I receptor. Cancer Res 65: 3781-3787, 2005.

37. Linnerth NM, Siwicky MD, Campbell CI, Watson KL, Petrik JJ, Whitsett JA and Moorehead RA: Type I insulin-like growth factor receptor induces pulmonary tumorigenesis. Neoplasia 11: 672-682, 2009.
38. Chong YM, Colston K, Jiang WG, Sharma AK and Mokbel K: The relationship between the insulin-like growth factor-1 system and the oestrogen metabolising enzymes in breast cancer tissue and its adjacent non-cancerous tissue. Breast Cancer Res Treat 99: 275-288, 2006.

39. Weber MM, Fottner C, Liu SB, Jung MC, Engelhardt D and Baretton GB: Overexpression of the insulin-like growth factor I receptor in human colon carcinomas. Cancer 95: 2086-2095, 2002.

40. Werner H, Shalita-Chesner M, Abramovitch S, Idelman G, Shaharabani-Gargir $\mathrm{L}$ and Glaser $\mathrm{T}$ : Regulation of the insulin-like growth factor-I receptor gene by oncogenes and antioncogenes: implications in human cancer. Mol Genet Metab 71: 315-320, 2000

41. Kuramoto H, Hongo A, Liu Y, Ojima Y, Nahamura K, Seki N, Kodama J and Hiramatsu Y: Immunohistochemical evaluation of insulin-like growth factor 1, receptor status in cervical cancer specimens. Acta Medica Okayama 62: 251-259, 2008. 